\author{
Military Technical College \\ Kobry Elkobbah, \\ Cairo, Egypt
}

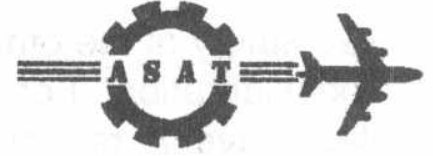

$8^{\text {th }}$ International Conference on Aerospace Sciences \& Aviation Technology

\title{
EVALUATION OF THE DYNAMIC PERFORMANCE OF ARTICULATED VEHICLES (CASE STUDY)
}

\author{
Y. H. HOSAMEL-DEEN", M. A. EL-HADDAD", M. M. MOUSSA"* and A. M. SHARAF"
}

\begin{abstract}
Recently the evaluation of articulated vehicles dynamic performance has been the focus of a significant research effort, where most of the tractors and semitrailers are manufactured separately each in a different place. However, the suitable combinations between them represent a major problem, especially in the military field where the payloads are characterized by unconventional weights and dimensions. The objective of this paper is to investigate the scientific basis for evaluation of the controllability and stability limits of such combinations. In order to achieve this goal, a theoretical analysis, computer simulation and field measurements have been carried out.

In the theoretical analysis, the dynamic performance measures of articulated vehicles have been discussed and analyzed. In the computer simulation, the validated models developed by UMTRI (University of Michigan Transportation Research Institute) have been used to evaluate these dynamic performance measures. In order to show the applicability of using these computer tools, a practical case is considered for an existing tractor-semitrailer combination used in the Egyptian army. The possible field measurements are done to obtain the needed input data. Other data are considered either from the manufacturer manuals, or by estimation using the published empirical methods. The practical case study shows the applicability of using this technology in the national scale.
\end{abstract}

\section{KEYWORDS}

ARTICULATED VEHICLES DYNAMIC - PERFORMANCE MEASURES.

\section{INTRODUCTION}

Nowadays the articulated heavy vehicles play an economically important role in the transportation process, and their numbers have been increasing for several decades. In the military field, the demands of transporting combat equipment that are characterized by unconventional weights and dimensions, necessitate using unconventional transporter. Not only the safety of these vehicles during different

\footnotetext{
* Associate Prof., Higher Technological Institute (HTI), Tenth of Ramadan City, EGYPT

** Associate Prof., Automotive Engineering Dept., Military Technical College, Cairo, EGYPT

***. Head of Automotive Engineering Dept., Military Technical College, Cairo, EGYPT

**** M. Sc., Automotive Engineering Dept., Military Technical College, Cairo, EGYPT.
} 
maneuvers is of prime interest, but also safety of the other vehicles and the highway infrastructure should be taken into consideration. For assessment of the related response measures of heavy vehicles, several researches in this field have been carried out, ([1], [2], [3]). In this paper the performance measures given in [2] are introduced as a scientific means for evaluation of the safety related measure for the heavy vehicles. A case study of an actual vehicle is also presented.

\section{DYNAMIC PERFORMANCE MEASURES FOR HEAVY VEHICI..ES}

The first set of performance measures that are used in a significant way in North America was developed for the Canadian Vehicles Weights and Dimensions study (Ervin and Guy, 1986), [1], adopted by "RTAC", (Road and Transportation Association of Canada). They were used to provide the technical foundation for regulatory changes introduced in most Canadian Provinces following the weights and dimensions study. Several years after the Vehicle Weights and Dimensions Study, (EL-Gindy, 1995), [2], the National Research Council of Canada (NRC) conducted a study which found it is necessary to modify RTAC performance measures in order to reveal the effect that significant change in certain tractor parameters had on the performance. Seven stability and control measures are to be introduced:

1- Handling performance.

2- Static rollover threshold (SRT).

3- Dynamic rollover stability:

a) Load transfer ratio (LTR).

b) Rearward amplification ratio (RWA).

4- Yaw damping ratio (YDR).

5- Friction demand:

a) Low speed friction demand (LFD).

b) High speed friction demand (HFD).

6- Lateral friction utilization (LFU).

7- Offtracking performance.

\subsection{Handling Performance}

Handling performance is a measure used for the evaluation of both controllability and stability of a given combination. It is evaluated by National Research council of Canada (NRC) method. The NRC three point measure, Fig.1, characterizes the handling diagram of a vehicle over a complete range of lateral acceleration, $A_{y}$. The diagram is constructed using the $\left.\left\{\left(L . r / U-\delta_{F w}\right), A_{y}\right)\right\}$ coordinate system, where $\left(\delta_{F W}\right)$ is the front wheel steer angle, $(L)$ is tractor or truck wheelbase, $(r)$ is the steady-state yaw rate and $(U)$ is the vehicle speed. It can be described as followed:

First point: This point addresses the level of lateral acceleration at which the vehicle transforms from understeer to oversteer. It should not be less than $18 \mathrm{~g}$, to ensure a reasonable level of lateral acceleration before the onset of oversteer. 
Second point: This point addressees the understeer coefficient, $K_{u}$, at a lateral acceleration of $0.3 \mathrm{~g}$. The coefficient is to be higher than the critical understeer coefficient, $\mathrm{K}_{\mathrm{ucr}}$, by a certain margin of safety. The critical understeer coefficient is defined as $\left(-\mathrm{Lg} / \mathrm{U}^{2}\right)$.

Third point: This point is designed to place upper and lower limits on the understeer coefficient $\mathrm{K}_{\mathrm{u}}$, at a lateral acceleration level of $0.15 \mathrm{~g}$, in order to ensure reasonable controllability of a heavy truck in the lower levels of lateral acceleration. It is held within a range from 0.0 to $2.0 \mathrm{deg} / \mathrm{g}$.

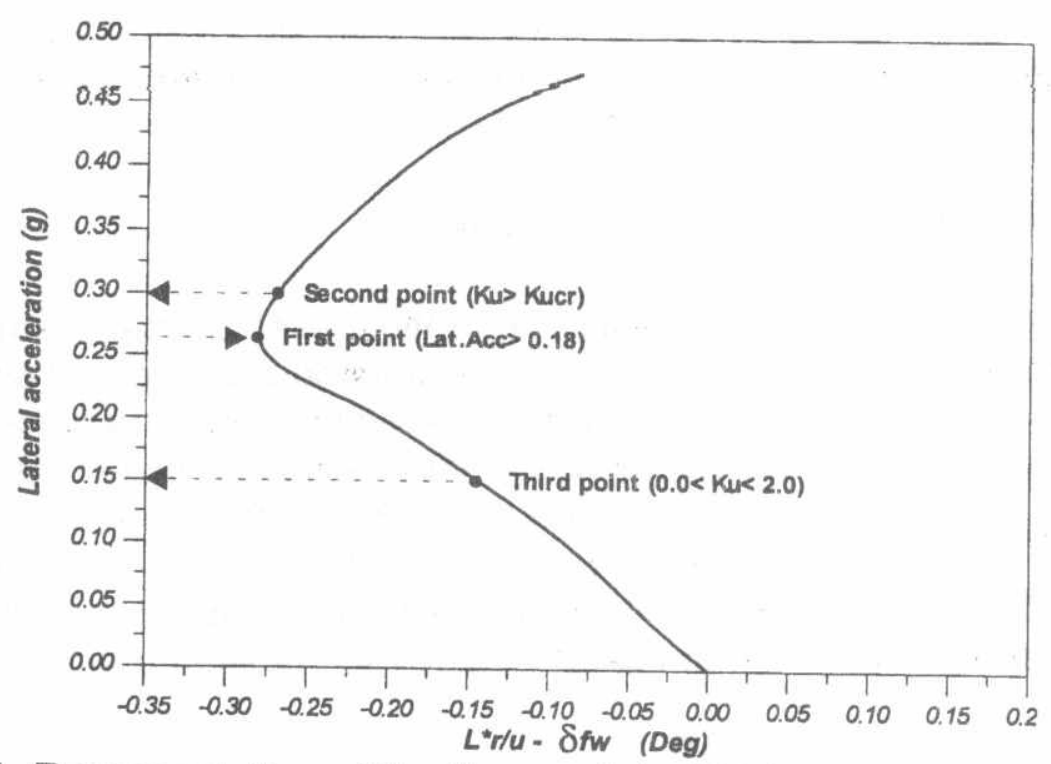

Fig.1. Representation of the three points (NRC) handling diagram.

\subsection{Static Rollover Threshold Measure (SRT)}

The common definition of the static rollover threshold is "The maximum lateral acceleration level in $\mathrm{g}$ units beyond which static rollover occurs". The recommended methods for the evaluation of the static rollover threshold are, [3]:

1-Measurement using tilt table.

2-Calculation using a validated static roll model.

The target value is $0.40 \mathrm{~g}$ minimum.

\subsection{Dynamic Rollover Stability Measures}

Dynamic rollover stability measure is evaluated by considering two different ratios, the first is the load transfer ratio, and the second is the rearward amplification ratio.

\subsubsection{Load transfer ratio (LTR) measure:}

The LTR is defined as the ratio of the absolute value of the difference between the sum of right wheel loads and the sum of left wheel load to the sum of all wheel loads.

$$
L T R=\sum\left(\left|F_{L}-F_{R}\right|\right) / \sum\left(F_{L}+F_{R}\right)
$$


Where $\sum$ Indicates summation over all of the vehicles axles except the tractor steering axle because of its relatively high roll compliance.

$F_{L}$ and $F_{R}$ represent the left and right vertical load at each axle except the tractor steering axle.

LTR measure is considered as the maximum of the absolute value of LTR. It serves as an indicator of the proximity to the total wheel lift-off. It should not exceed 0.6

\subsubsection{Rearward amplification ratio (RWA) measure}

Defined as the ratio of the peak value (positive or negative) of lateral acceleration achieved at the mass center of the rearmost trailer to that developed at the mass center of the tractor. The target value should not exceed 2.2

\subsection{Yaw Damping Ratio Measures (YDR)}

It characterizes the directional damping ratio level of the rearmost trailer of articulated vehicle. Low damping results in prolonged swaying and could lead to an accident. Also it describes how rapidly the oscillations of lateral acceleration of the rearmost trailers of an articulated vehicle diminish after pulse steer input. This measure is evaluated at a vehicle speed of $100 \mathrm{Km} / \mathrm{hr}$ by applying a steering wheel pulse input of $80^{\circ}$ over a $0.1 \mathrm{sec}$ time interval. From the successive peaks of lateral acceleration decay of the rearmost trailers, a damping ratio is calculated using the standard logarithmic decrement procedures. The recommended target value is 0.15

\subsection{Friction Demand Measure}

Friction demand measure is defined by the following equation:

$$
\mu=\left|\left(\sum F_{y} / \cos \Gamma\right) / \sum F_{z}\right|
$$

where: $\mu$ is the instantaneous friction coefficient at the tractor drive axles' tires.

$F_{y}$ is the resultant shear force arising simply due to the curvilinear travel.

$\cos \Gamma$ is the cosine of articulation angle.

$F_{Z}$ is the vertical load imposed on those tires

The friction demand measure describes the tire/road friction levels measured at the drive axles of the tractor or straight truck. Excessive friction demand is a cortributing factor to tractor jackknife and also results in excessive tire wear. Liftable axles are often used to improve cornering ability. The recommended target value is 0.3

\subsubsection{Low speed friction demand (LFD)}

LFD calculated during low speed path follow maneuver. This is a right hand $90^{\circ}$ turn at $5.0 \mathrm{~km} / \mathrm{hr}$ where the tractor's front axle center point tracks an arc of $9.8 \mathrm{~m}$ radius (approximately an $11 \mathrm{~m}$, outside wheel path radius). It should be noted that the peak value of the low speed friction demand is taken which represents LFD measure.

\subsubsection{High speed friction demand (HFD)}

HFD is calculated during high-speed $(100 \mathrm{Km} / \mathrm{hr})$ path change maneuver, the peak value of the HFD is taken, which represents high speed friction demand measure. 


\subsection{Lateral Friction Utilization (LFU)}

Characterizes the highest level of the lateral friction utilization at an axle or group of axles of a vehicle during low and high speed turns maneuvers. The axles or axle group is referred to as the "critical axle(s)". This measure indicates which axle or group of axles is expected to lose lateral adhesion (available tire road friction) during a given maneuver. The tires of the axle or axle group that achieve lateral friction levels of $100 \%$ are said to be saturated.

\begin{tabular}{|l|l|}
\hline Saturated front axle tires & Result in loss of steering control. \\
\hline Saturated drive axle tires & Result in jackknife \\
\hline Saturated trailer tires & Result in trailer swaying. \\
\hline
\end{tabular}

The measure also provides information on weather or not a particular maneuver can be performed at all given particular road surface coefficient of friction.

\subsection{Offtracking Performance measures.}

Offtracking is defined as the lateral offset of the path taken by the trailing axles of a vehicle combination from the path taken by the tractor's steering axle in a steady turn. Each of these aspects is examined in a constant-radius turn maneuver. For the steady-state options, the vehicle is assumed to be turning continuously in and to have achieved a steady-state response. For the low-speed transient option, the maneuver includes a straight line "entry" and straight line "exit" to the constant radius turn. The path of the centerline of each axle and of the rearmost extremity of the vehicle are determined by UMTRI simplified offtracking model.

\section{COMPUTER SIMULATION MODELS}

In this study, three validated models, which are developed by "UMTRI", can be used to evaluate the mentioned dynamic performance measures. These models are yaw/roll model, static roll model and simplified offtracking model, [4].

\section{Yaw/Roll Model:}

The Yaw/roll model was developed for the purpose of predicting the directional and roll response of single and multiple-articulated vehicles engaged in steering maneuvers, which approach the rollover conditions. It should be noted that the model does not permit the simulation of braking maneuvers. The model is unique in the sense that it permits the analysis of unconventional vehicle layouts. The equations of motion are developed in such a fashion that it is possible to use the model for simulating the vehicles with any number of placement of wheels and tires, any number of units and articulation points or any of the particular hitch mechanisms.

The computer code permits the simulation of vehicles with up to three articulation points (i.e. four sprung masses) and 11 axles. In the model, the forward velocity of the lead unit is assumed to remain constant during the maneuver. Hence, each sprung mass is treated as a rigid body with five degrees of freedom lateral, vertical, yaw, roll, and pitch. The axles are treated as beam axles, which are free to roll and bounce with respect to sprung mass to which they are attached. The validation of yaw/roll model was carried out, through which the model output was found to be in a good agreement with those measured responses, [5]. 


\section{PRACTICAL CASE STUDY "EVALUATION OF THE DYNAMIC PERFORMANCE OF A GIVEN COMBINATION"}

The case study deals with a combination from the armed forces, which consists of tractor and semitrailer. A complete study was made to show the possibility of making use of these models to provide complete dynamic evaluation. The area of work is divided into three parts, the first deals with the different ways used for getting the simulation input data, the second is the output of the models through different maneuvers, the last one is the results analysis and the final evaluation.

\subsection{Getting Simulation Input Data}

The major step in the simulation procedures is to get the input data of the models. The more accurate input data, the more accurate results are obtained. The input data can be classified into three groups:

1.Data collected from the manufacturer manuals.

2.Data measured, which are difficult to get from the manufacturer.

3.Data calculated or estimated which are difficult to obtain by measurements.

It should be noted that, a summary of the obtained input data is given in appendix-A. In the following sections, the methods of obtaining these data are highlighted.

\subsubsection{Data obtained from the manufacturer manuals, [6]:}

1. Sprung mass parameters: [number of sprung mass units]. $\cdots, \ldots \ldots$

2. Unsprung mass (axles) parameters: [number of axles and tandem axle spread].

3. Articulation parameters: [type of articulation point, height of the articulation point and location of the articulation point from the tractor tandem axle centerline].

4. Suspension parameters: [suspension lateral spread, shock absorber (exist or not), spring stiffness and suspension type].

5. Tire parameters: [track width, dual tire spacing, Inflated and loaded dimensions (overall width and diameter), tread pattern shape, and load at inflation pressure].

6. Steering system parameters: [steering gear box ratio].

7. Payload parameters: [dimensions, weight and C.G. location].

\subsubsection{Measured parameters:}

The following parameters are obtained using truck load scale, which is shown in Fig.2. This scale is capable of measuring weights up to $(100,000 \mathrm{Kg})$, its length and width are $(18 \mathrm{~m}, 3 \mathrm{~m})$ respectively. Before measurement, the scale was calibrated to measure a known weight. The error in reading was found to be $0.01 \%(10 \mathrm{~kg})$. Dial indicator with accuracy of $0.01 \mathrm{~mm}$ and range output $50 \mathrm{~mm}$ was used to measure the position of the axles relative to the ground and frame. Measured parameters are:

1- Tractor only:

a- Total weight of the tractor.

b- Load on the tractor front axle only.

c- Combined load on the tractor rear axles only.

d- Load on the tractor front axle, when its rear end is lifted at slope (15 [leg). 
2- Tractor combined with empty semitrailer:

a- Total weight of the tractor only.

b- Combined load at the semitrailer axles.

c- Combined load at one side of the semitrailer axles.

3- Tractor combined with semitrailer loaded with tank M88.

a- Weight of the test payload (Tank M88).

b- Combined load at one side of the semitrailer axles.

c- Corresponding axle deflection relative to the frame

d-Corresponding axle deflection relative to the ground

4- Tractor combined with semitrailer loaded with tank M109:

a- Weight of the test payload (Tank M109).

b- Combined load at one side of the semitrailer axles.

c- Corresponding axle deflection relative to the frame.

d-Corresponding axle deflection relative to the ground.

5- Tractor combined with semitrailer loaded with tank M1A1:

a- Weight of the test payload (Tank M1A1).

b- Combined load at one side of the semitrailer axles.

c- Corresponding axle deflection relative to the frame.

d-Corresponding axle deflection relative to the ground.

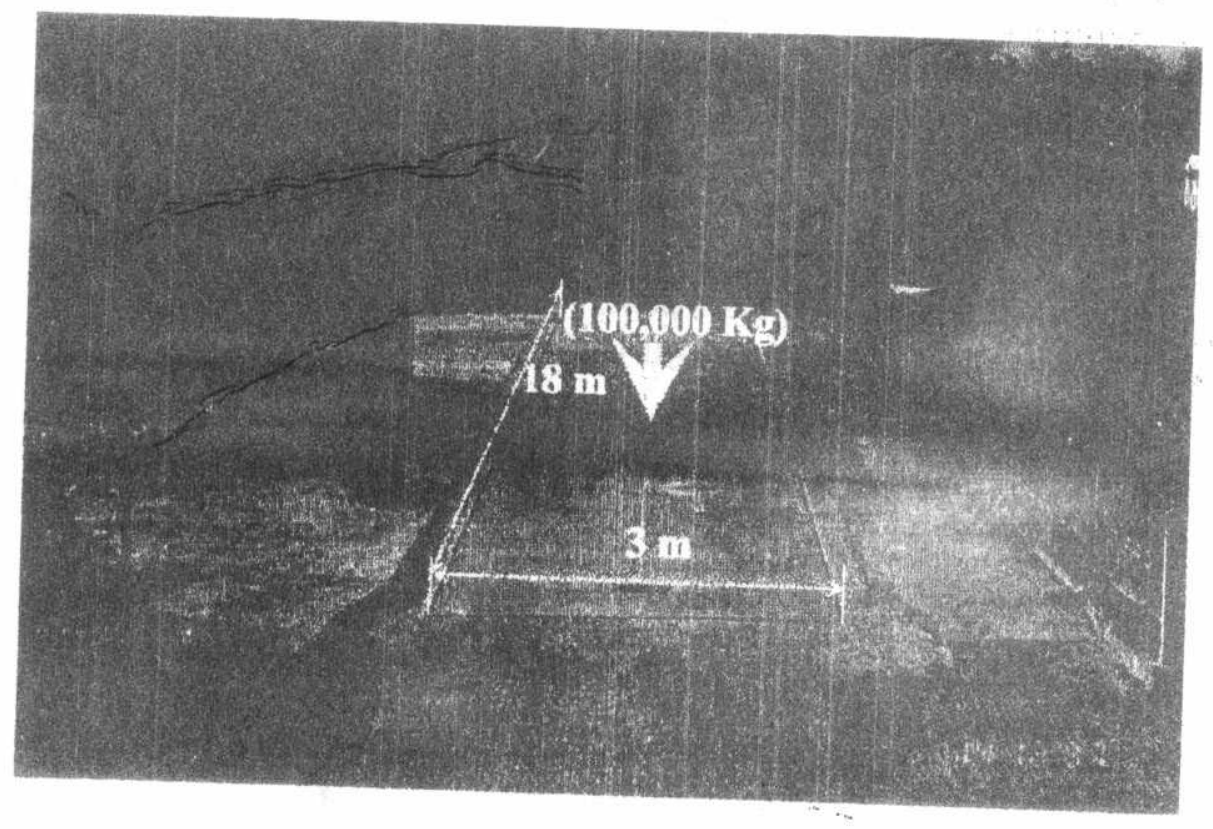

Fig.2. Truck load scale capacity and dimensions

\subsubsection{Estimated data based on measurement and/or calculation:}

The major set of input data is obtained either by calculation or estimation, based on the data collected from technical manuals or measured. These data are listed below:

1. Sprung mass parameters*: [weight, roll, pitch, yaw moment of inertia and C.G location for each unit].

2. Unsprung mass parameters: [weight** roll mome

C.G. of the unit which is mors: [weight ${ }^{* *}$, roll moment of inertia*, axle location from 
3. Articulation parameters: [articulation point roll stiffness ${ }^{\star *}$ and location from each unit sprung mass C.G.*].

4. Suspension parameters: [roll center height ${ }^{* *}$, roll steer coefficient ${ }^{\star *}$, auxiliary roll stiffness $^{* *}$, viscous damping coefficient ${ }^{* *}$, spring stiffness ${ }^{*}$ and suspension coulomb friction**].

5. Tire parameters: [tire vertical stiffness*, cornering stiffness*, aligning torque stiffness ${ }^{*}$ and overturning stiffness $\left.{ }^{* *}\right]$.

6. Steering system parameters: [steering system stiffness ${ }^{\star *}$, tie rod linkage stiffness $^{\star *}$ and mechanical trail**].

7. Miscellaneous parameters ${ }^{* *}$ : [tractor frame torsional stiffness, tractor frame Coulomb friction and Lash in fifth wheel plates].

It should be noted that, $\left({ }^{*}\right)$ is used for calculated data and $\left(^{* \star}\right)$ for estimated clata.

\section{1- Sprung mass parameters:}

A- Tractor sprung mass parameters:

(1)Tractor sprung mass weight:

The empty tractor weight is obtained by the scale, Fig.3, and the unsprung mass weight are estimated as follow, [1]:

- Tractor front axle: 1,200 lbs.

- Tractor drive axle: $2,300 \mathrm{lbs}$.

The tractor sprung mass is calculated as follow:

Sprung mass weight $=$ Empty tractor weight - total unsprung mass weight

(2) Tractor sprung mass C.G. location:

(a)Tractor sprung mass longitudinal C.G. location:

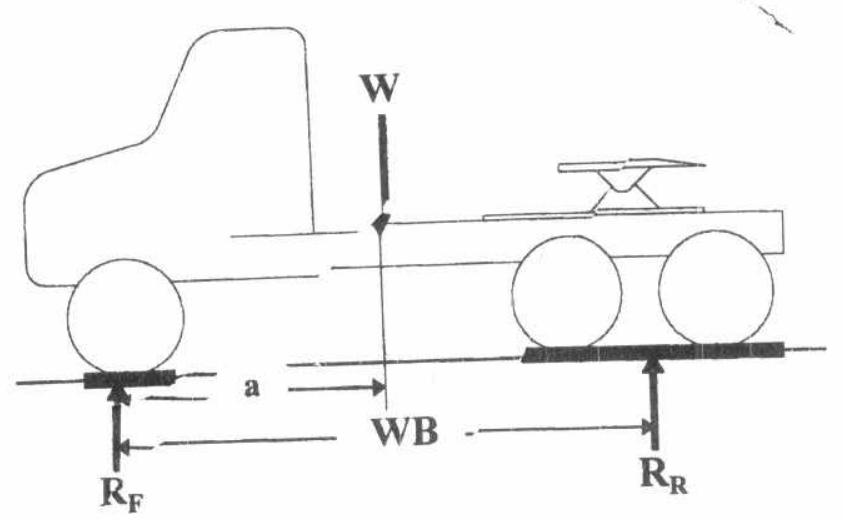

Fig.3. Determination of tractor longitudinal C.G. location

The simplest method to determine the longitudinal C.G. location is by using truck load scale. Measuring the reactions under the front, $\left(R_{F}\right)$, and tandem rear axles, $\left(R_{R}\right)$, separately. Then, the portions of the tractor sprung mass weight on each axle are calculated as follow:

$$
\begin{gathered}
W_{S F}=R_{F}-W_{a x F} \\
W_{S R}=R_{R}-W_{a x R}
\end{gathered}
$$


where:

$\mathrm{W}_{\mathrm{SF}}, \mathrm{W}_{\mathrm{SR}}$ are the portions of the tractor sprung weight on the front and combined rear axles respectively.

$\mathrm{W}_{\mathrm{axF}}, \mathrm{W}_{\mathrm{axR}}$ are the unsprung mass weights of the tractor front, and rear axles.

The tractor sprung mass C.G. location is calculated from the following equation:

$$
a=\frac{W_{S R}}{\left(W_{S F}+W_{S R}\right)} \times W B
$$

Where, $a$, is the longitudinal C.G. location of the tractor sprung mass from front axle WB is the tractor wheelbase, as shown in Fig. 3.

\section{(b) Tractor sprung mass C.G. height:}

A commonly used technique to determine this parameter is illustrated in Fig.4, where the following procedures are made:

1. The tractor front axle only is put on the load scale.

2. The rear end of the tractor is lifted by a vertically applied force (using crane), the load at the tractor front axle (F1) is Measured, Fig.5, and then C.G. height is calculated from the following equation:

$$
L_{o}=\left(\frac{L_{1} \times F_{1}}{W}-L_{2}\right) \times \operatorname{ctn} \theta-\frac{F_{1} \times L_{3}}{W}
$$

All the notations are shown in Fig.4.

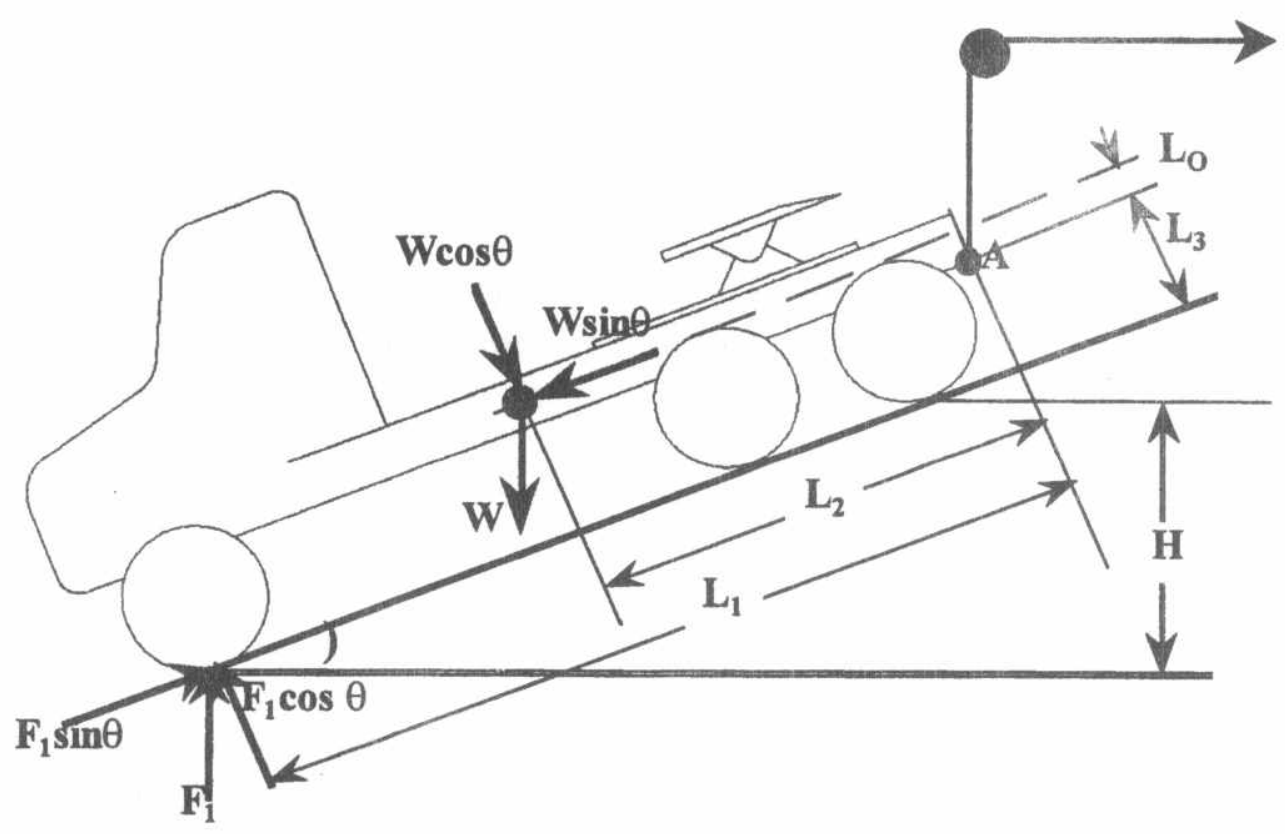

Fig.4. Vertical C.G. height Position measurement 


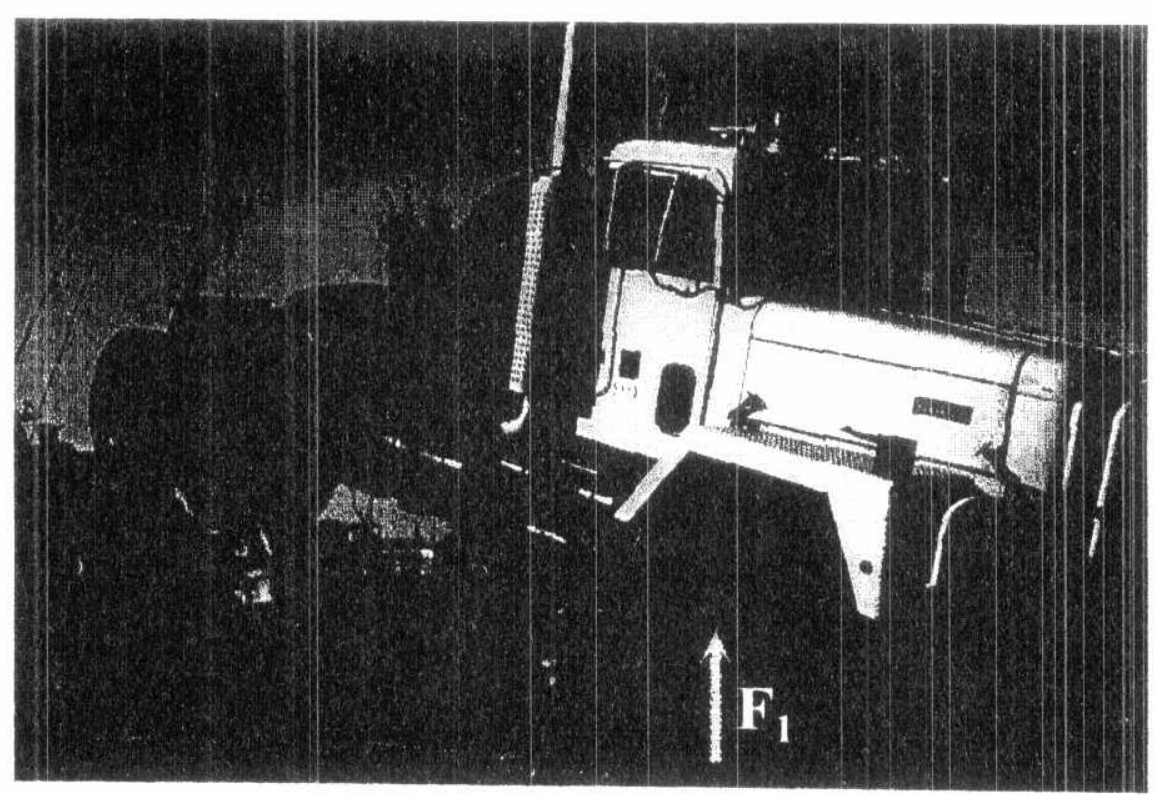

Fig.5. Measurement of the tractor front axle load when it is lifted

(3) Estimation of the moments of inertia:

(a) Roll moment of inertia:

The tractor sprung mass roll moment of inertia is determined according to the following equation, [1]:

$$
I_{x x}=2.178 \times W_{s}
$$

where: $I_{X x}$ is the tractor sprung mass roll moment of inertia, [lb.in. $\left.\sec ^{2}\right]$.

$\mathrm{W}_{\mathrm{S}}$ is the tractor sprung mass, [L.b.].

(b) Pitch and Yaw moments of inertia:

The sprung mass pitch and yaw moments of inertia, $l_{j j}(j=y, z)$, are determined from the ollowing empirical formula, [1]:

$$
I_{j j}=\left[\left(W_{f}+0.4 W_{r}\right) X^{2}+0.6 W_{r}(L-X)^{2}\right] / g
$$

Where: Subscript $j=Y, Z$ for pitch and yaw moment of inertia respectively.

$W_{f}$ and $W_{r}$ are partial sprung weights supported by front and rear axles.

$X,(L-X)$ are the distances from the sprung mass center of gravity to the tractor front and rear axles respectively.

$\mathrm{g}$ is the gravitational acceleration $\left(386 \mathrm{in} / \mathrm{sec}^{2}\right)$.

\section{B- Semitrailer sprung mass Parameters:}

(1) Siemitrailer sprung mass weight:

Referring to Fig.6, and using the load scale, the tractor weight with and without the semitrailer is measured $\left(W_{t s}, W_{t}\right.$ respectively). The reaction at the fifth wheel $\left(W_{5}\right)$ then is given by $\left(W_{5}=W_{t s}-W_{t}\right)$. The reaction at the combined semitrailer axles is measured $\left(R_{\mathrm{axT}}\right)$. Knowing $\left(W_{5}\right)$ and $\left(R_{\mathrm{axT}}\right)$, and using the same procedures for truck sprung mass weight determination, the sprung mass weight of the semitrailer is obtained. It should be noted that, Semitrailer unsprung mass weight for each axle $=1,760: 2,000$ [Lb.], [1]. 


\section{(2) Semitrailer sprung mass C.G. location}

\section{(a) Semitrailer sprung mass longitudinal C.G. location}

The distribution of the semitrailer sprung mass weight on both the fifth-wheel, $\left(W_{5}\right)$, and at the rear axles, $\left(R_{s, a x T}\right)$, can be calculated, then the semitrailer sprung mass longitudinal C.G. location $\left(L_{1}\right)$ is calculated as follow, Fig.6:

$$
L_{l}=\left(\frac{R S, a x T}{W_{S}+R s, a x T}\right) \times L
$$

Where, $W_{5}, R_{S, a x t}$ are the portion of the semitrailer sprung mass on the fifth-wheel and the combined rear axles respectively.

$L$ is the semitrailer wheelbase.

$L_{1}$ is the semitrailer sprung mass longitudinal C.G. location (from fifth wheel).

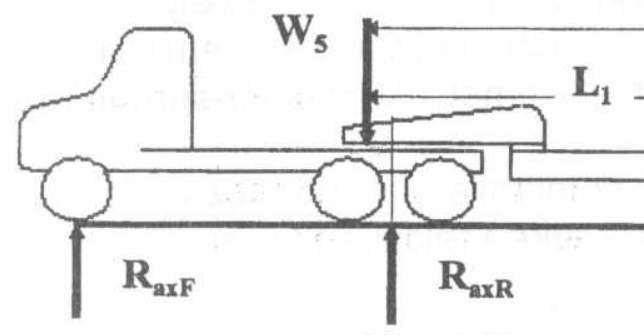
$\mathbf{L}$

Fig.6. Empty tractor-semitrailer axle loads

(b) Semitrailer sprung mass C.G. height:

As the semitrailer sprung mass C.G. height is not given by the manufacturer, it can be estimated as the height above ground of the main semitrailer longitudinal beams centerline, [1].

\section{(3) Semitrailer sprung mass moments of inertia:}

Based on the work in reference [1], and the published data of moments of inertia of different semitrailers, [7], semitrailer roll, pitch and yaw moment of inertia can be estimated from Fig.7.

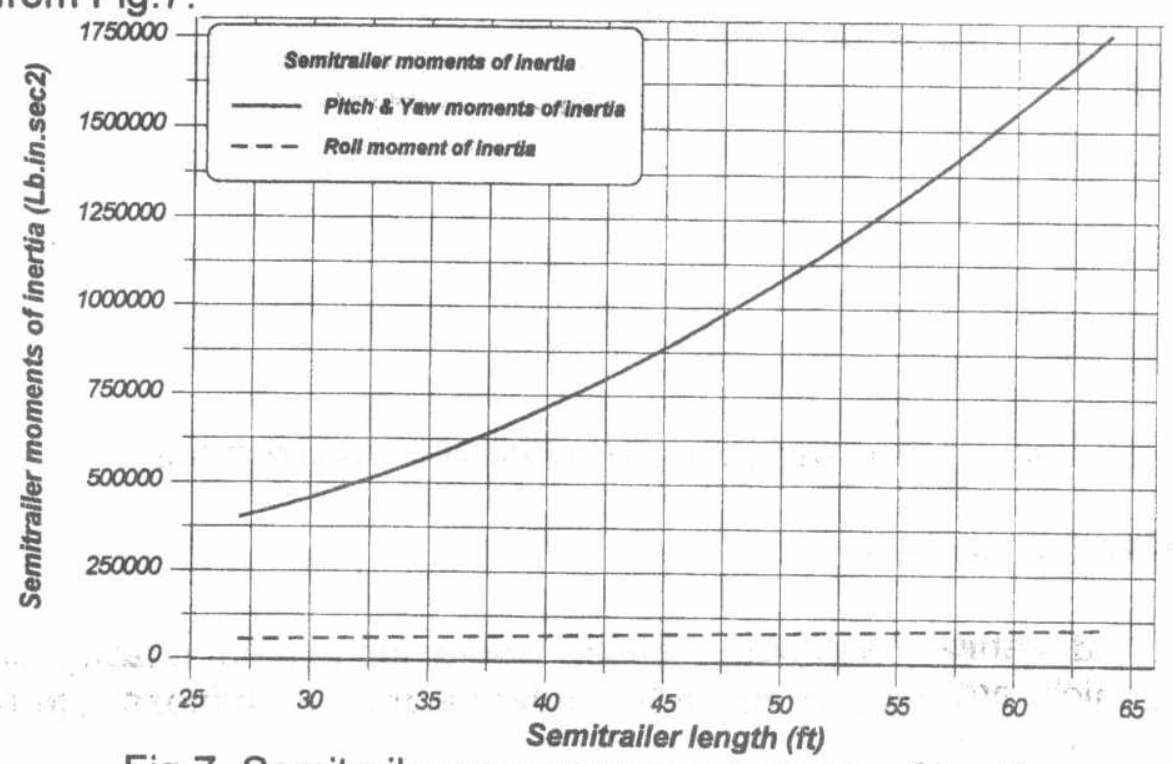

Fig.7. Semitrailer sprung mass moments of inertia 


\section{(4) Combined semitrailer and payload moments of inertia}

The combined roll, pitch, and yaw moments of inertia of the combined semitrailer and payload Ixxc, lyyc, Izzc about the axes, $X_{c}, Y_{c}, Z_{c}$ passing through the combined sprung mass center of gravity $\left(x_{c}, y_{c}, z_{c}\right)$, Fig. 8 , are given by the following equations.

$$
\left.\begin{array}{l}
I_{x x c}=I_{x x p}+m_{p}\left\{\left(y_{p}-y_{c}\right)^{2}+\left(z_{p}-z_{c}\right)^{2}\right\}+I_{x x s}+m_{s} *\left\{\left(y_{s}-y_{c}\right)^{2}+\left(z_{s}-z_{c}\right)^{2}\right\} \\
I_{y y c}=I_{y y p}+m_{p}\left\{\left(x_{p}-x_{c}\right)^{2}+\left(z_{p}-z_{c}\right)^{2}\right\}+I_{y y s}+m_{s} *\left\{\left(x_{s}-x_{c}\right)^{2}+\left(z_{s}-z_{c}\right)^{2}\right\} \\
I_{z z c}=I_{z z p}+m_{p}\left\{\left(x_{p}-x_{c}\right)^{2}+\left(y_{p}-y_{c}\right)^{2}\right\}+I_{z z s}+m_{s} *\left\{\left(x_{s}-x_{c}\right)^{2}+\left(y_{s}-y_{c}\right)^{2}\right\}
\end{array}\right\}
$$

where:

$I_{x x p}, I_{y y p}, I_{z z p}$ are Payload roll, Pitch and yaw moments of inertia about the axes $X_{p}, Y_{p}$, $Z_{p}$ passing through the payload center of gravity $\left(x_{p}, y_{p}, z_{p}\right)$ respectively.

$I_{x x s}, I_{y y s}, I_{z z s}$ are empty semitrailer sprung mass roll, pitch, and yaw moments of inertia about the axis Xs, Ys, Zs passing through the empty semitrailer sprung mass center of gravity ( $x s, y s, z s)$, respectively.

$m_{p}, m_{s}$ are the masses of the payload, and empty semitrailer sprung mass.

$(X, Y, Z)$ are reference axes, where any dimension is taken relative to them.

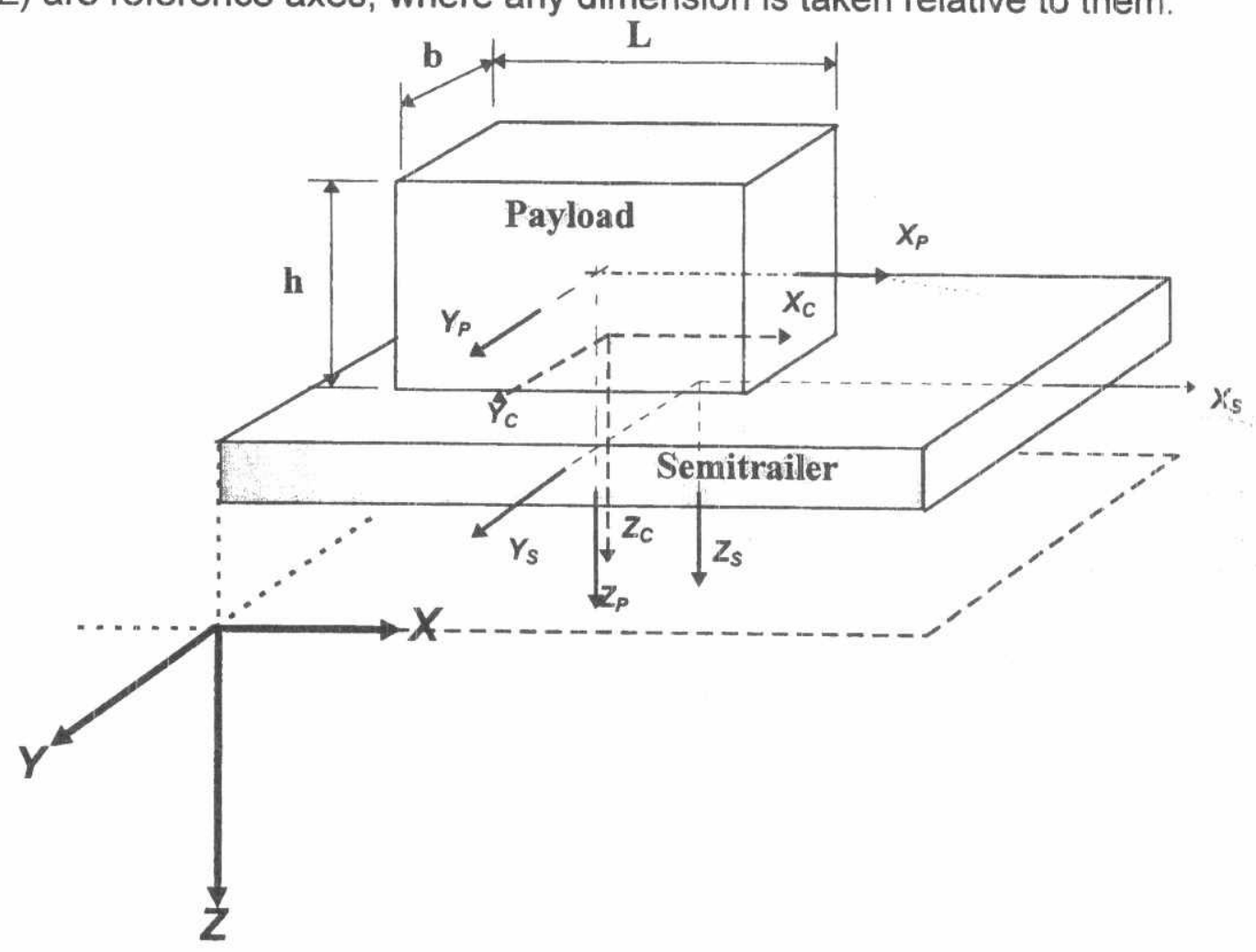

Fig.8. Combined payload semitrailer sprung mass

\section{2- Suspension parameters:}

The developed vehicle simulations require some input data relating suspension properties, which are spring rates, roll center height, roll stiffness, lateral stiffness and roll steer coefficient. 


\section{A-Semitrailer Spring rate measurement}

For the case studied it is difficult to get the semitrailer springs rate from the manufacturer. So an approximate technique is used to roughly measure the spring stiffness of the suspension when it is mounted on the vehicle, [8], [9]. The idea of this technique is to apply a vertical load to the semitrailer frame rails, and measure the appropriate displacement of the suspension spring against the existing load. In order to measure the semitrailer suspension spring stiffness, Fig.9, 10, the load versus spring deflection is measured and obtained by using different payloads. The corresponding deflection for each load is measured using a dial indicator between the axle and the frame, Fig. 11.

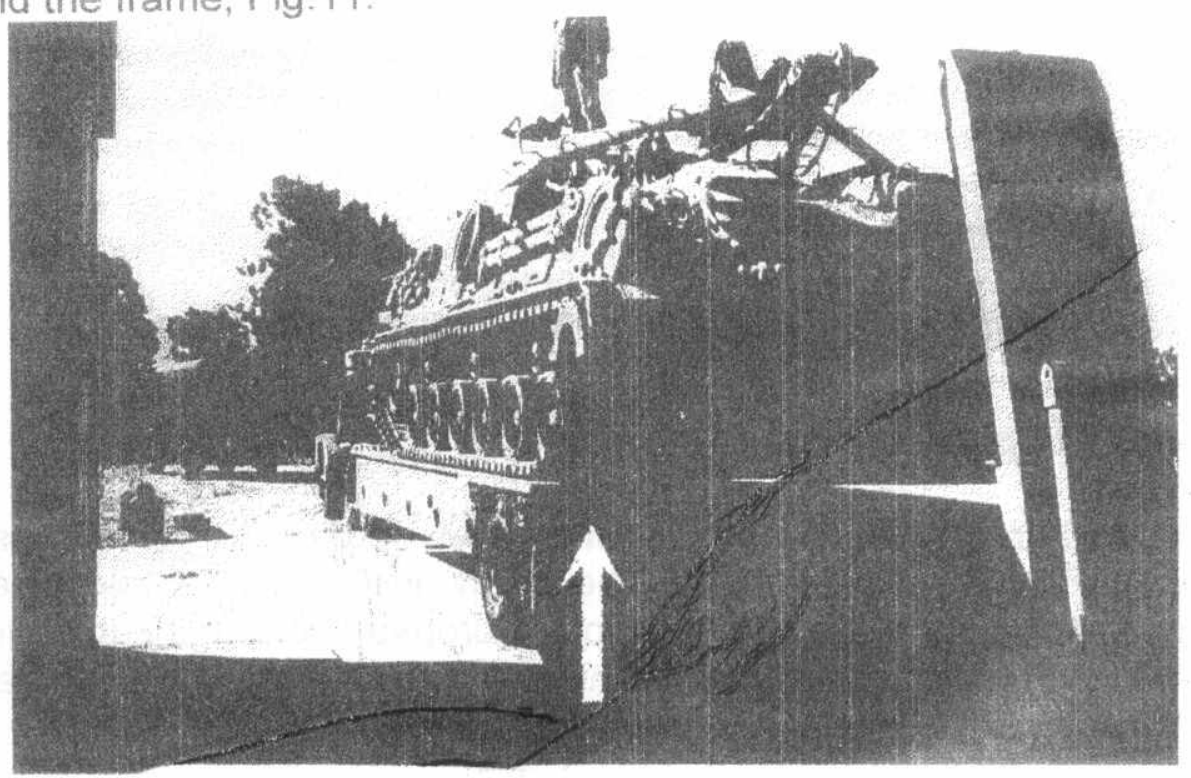

Fig.9. Measurement of the load when loaded with tank "M88"

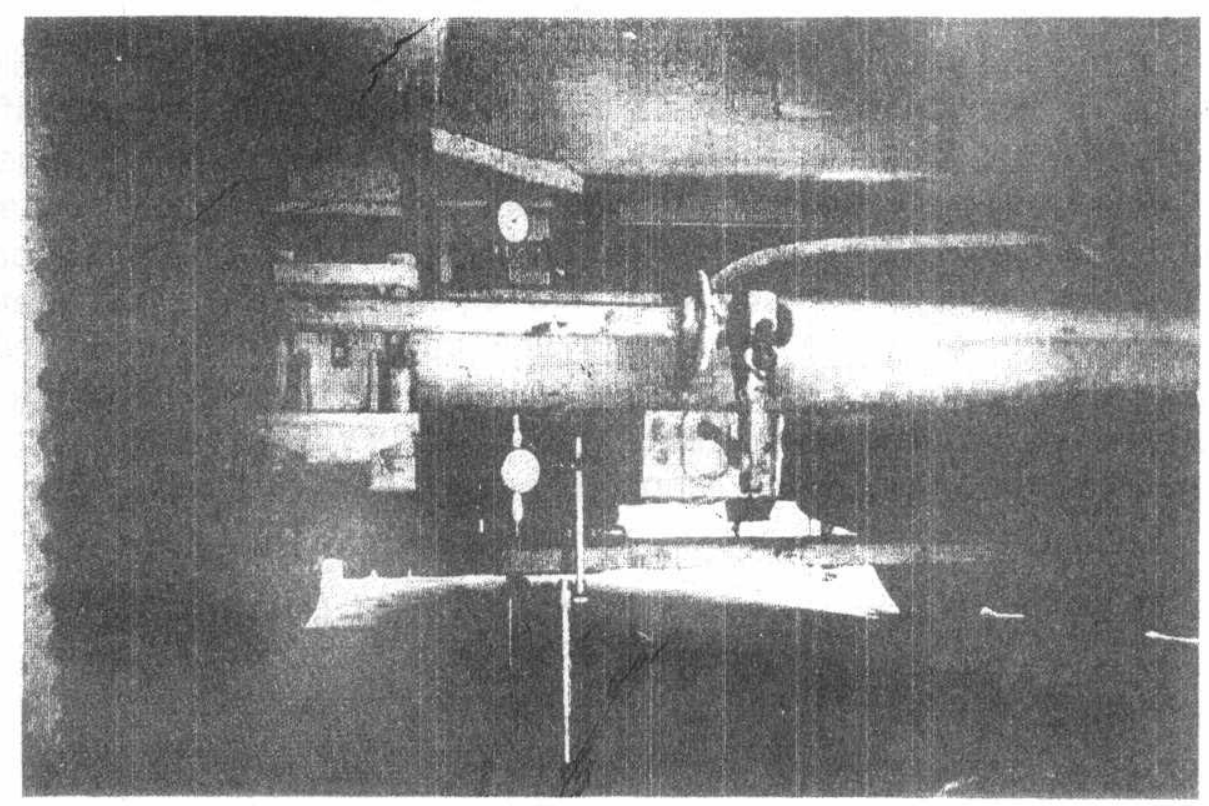

Fig. 10. Measurement of the corresponding axles deflection 


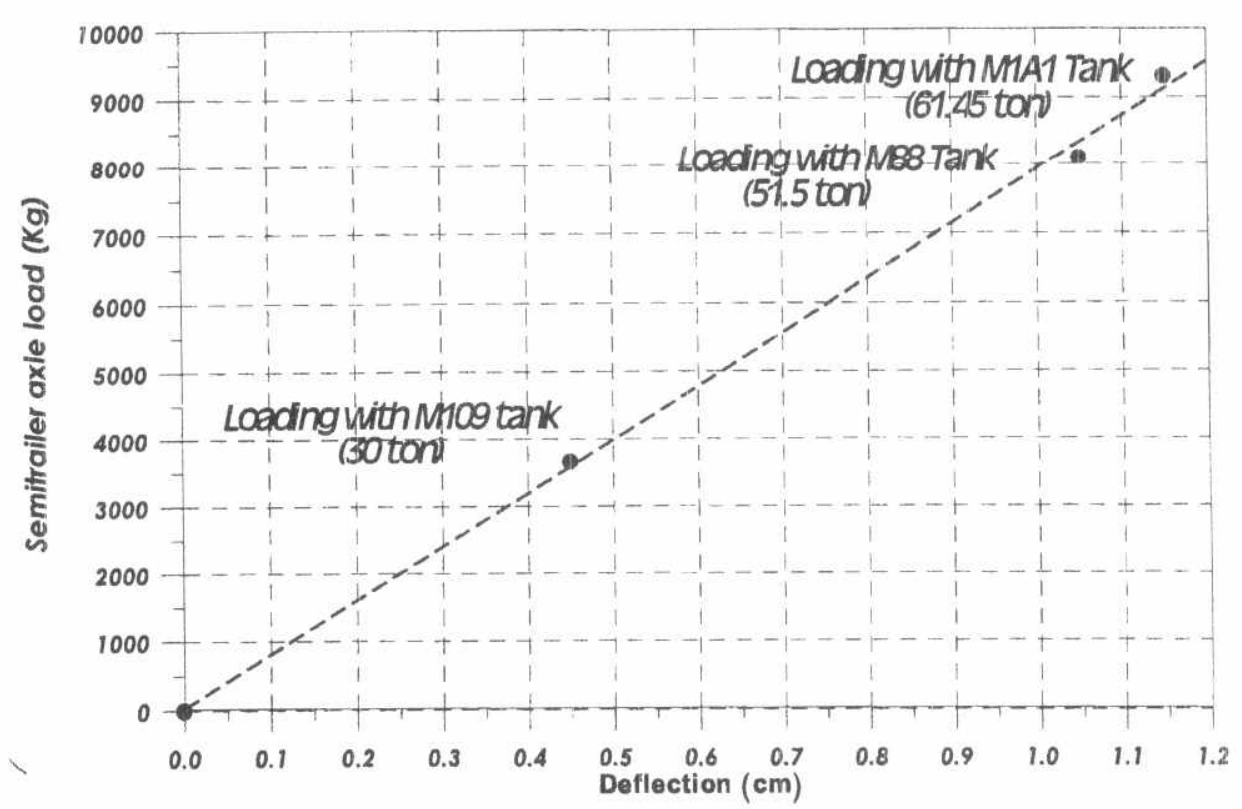

Fig.11. Semitrailer suspension characteristics.

\section{B- Roll stability parameters}

Data obtained from the measurement of ninety-four heavy vehicle suspension was presented by C. B. Winkler, [10]. The study includes a generic description of the suspension including class, spring type, European or American origin, load rating and test load, measured roll-center height, roll stiffness (total and auxiliary), and lateral stiffness and roll steer coefficient-are reported.

\section{3-Tire parameters.}

\section{A-Tire cornering and self-aligning torque stiffness}

A simple empirical model was created for both cornering and self aligning torque stiffness as a function of load, inflation pressure, and tread element stiffness factor. The tread element stiffness factor was developed by considering the tread in the contact area during cornering to be under unilateral shear. It was next assumed that the tread elements in this contact region behaved like rubber block bonded to two parallel plates, with one plate being tire casing and the other plate being the roadway. A shear stiffness per unit footprint length term, called tread stiffness factor was calculated using non-skid depth, tread width, and net-to-gross ratio tire parameters. Tread rubber shear modulus of $1.5 \mathrm{MPa}$ was assumed.

The empirical model used for cornering stiffness, [11]:

$$
\left.C_{S}=C_{O}+{ }^{\prime} C_{l} \times F_{Z}\right)+\left(C_{2} \times F_{Z}^{2}\right)+\left(C_{3} \times T S F\right)
$$

The empirical model ised for self-aligning torque stiffness, [11]:

$$
A T S=1_{O}+\left(A_{1} \times F_{Z}\right)+\left(A_{2} \times F_{Z}{ }^{2}\right)+\left(A_{3} \times P\right)+\left(A_{4} \times T S F\right)
$$


Where:

$\mathrm{C}_{\mathrm{S}}$ is the cornering stiffness, (KN/Deg.).

$\mathrm{F}_{\mathrm{Z}}$ is the tire load, (KN).

TSF is the tread stiffness factor, (TSF= G.TW.NTG/NSD).

$G$ is the rubber shear modulus, (Mpa).

TW is the tread width, $(\mathrm{cm})$.

NTG is the tread pattern net-to-gross ratio.

NSD is the tread non skid depth, $(\mathrm{cm})$.

$\mathrm{C}_{0}, \mathrm{C}_{1}, \mathrm{C}_{2}, \mathrm{C}_{3}$ are constants that are given below.

$C_{O}=-0.71602669, C_{1}=0.16299723, C_{2}=-0.002012783, C_{3}=0.00240035$

ATS is the aligning torque stiffness, (N.m/Deg.).

$P$ is the tire inflation pressure, (bar).

$A_{0}, A_{1}, A_{2}, A_{3}, A_{4}$ are constants that are given below.

$A_{0}=11.91324890, A_{1}=6.13365504, A_{2}=0.02270090, A_{3}=-13.17650471$, $A_{4}=0.01827841$

\section{B- Tire vertical stiffness.}

The tire vertical stiffness is calculated from the following equation:

$$
\text { Tire vertical stiffness }=\frac{\text { Rated capacity load }}{\text { free radius }- \text { static loaded radius }}
$$

\section{4- Steering system parameters}

STEERING SYSTEM STIFFNESS:

This value describes the stiffness at the road wheel when the steering wheel is held fixed. It is considered as a constant value equal (11000. Lb.in/deg), [4]

THE TIE ROD LINKAGE STIFFNESS:

This value describes the stiffness at the right road wheel when the left road wheel remains stationary. It is considered as a constant value (11000. Lb.in/deg), [4]

MECHANICAL TRAIL:

The mechanical trail equal to the caster angel times the front tire radius. A positive value corresponds to positive caster. It is considered as a constant value (1 in), [4]

\subsection{Computer Simulation and Performance Measures Output}

The input data, obtained in section (4.1), are fed to both the yaw/roll and static roll model. Evaluation of the dynamic performance of the studied combination during different maneuvers based on RTAC and NRC methods, which are summarized in section2, are given in table1. 
Table 1. Overall evaluation based on RTAC performance measures

\begin{tabular}{|c|c|c|c|c|c|c|c|c|}
\hline \multicolumn{4}{|c|}{ Performance measures } & Result & \multicolumn{2}{|c|}{ Limit } & \multicolumn{2}{|c|}{ Evaluation } \\
\hline \multirow{4}{*}{ a } & \multicolumn{3}{|c|}{ Static rollover threshold, [g], (by Static roll model) } & 0.46 & 0.40 & $\min$. & Pass & $\sqrt{ }$ \\
\hline & \multicolumn{3}{|c|}{ Static rollover threshold, [g], (by yaw/roll model). } & 0.522 & 0.40 & $\min$. & Pass & $\sqrt{ }$ \\
\hline & \multicolumn{3}{|c|}{ Dynamic load transfer ratio, (LTR). } & 0.333 & 0.6 & $\max$. & Pass & $\checkmark$ \\
\hline & \multicolumn{3}{|c|}{ Rearward amplification ratio, (RWA). } & 1.26 & 2.2 & $\max$. & Pass & $\checkmark$ \\
\hline \multirow{3}{*}{ b } & \multirow{3}{*}{$\begin{array}{c}\text { Three point handling } \\
\text { characteristics } \\
\text { (NRC) }\end{array}$} & 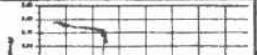 & Poin & 0.225 & \multicolumn{2}{|c|}{$>0.18 \mathrm{~g}$} & Pass & $\checkmark$ \\
\hline & & 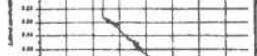 & Point (B) & -0.063 & \multicolumn{2}{|c|}{$\mathrm{Ku}>-3.98$} & Pass & $\checkmark$ \\
\hline & & $=1.214$ & Point (C) & 0.908 & \multicolumn{2}{|c|}{$2.0>\mathrm{Ku}>0.0$} & Pass & $\checkmark$ \\
\hline \multirow{3}{*}{ c } & \multicolumn{3}{|c|}{ Maximum low speed offtracking, [m], (LOF). } & 3.697 & 5.0 & $\max$. & Fass & $\checkmark$ \\
\hline & \multicolumn{3}{|c|}{ Transient high speed offtracking, [m], (TOF). } & 0.385 & 0.8 & $\max$. & Fass & $\checkmark$ \\
\hline & \multicolumn{3}{|c|}{ High speed steady-state offtracking, [m], (HOF). } & 0.391 & 0.46 & $\max$. & Fass & $\checkmark$ \\
\hline \multirow[t]{2}{*}{ d } & \multicolumn{3}{|c|}{ Low speed friction demand, (LFD). } & 0.117 & 0.3 & $\max$. & Fass & $\checkmark$ \\
\hline & \multicolumn{3}{|c|}{ High speed friction demand, (HFD). } & 0.173 & 0.3 & $\max$. & Fass & $\checkmark$ \\
\hline \multirow[t]{2}{*}{ e } & \multicolumn{3}{|c|}{$\begin{array}{r}\text { Lateral friction utilization, at low speed, (LFU). } \\
\text { Axle group }\end{array}$} & $\begin{array}{r}87 \% \\
1: 1 \\
\end{array}$ & $80 \%$ & $\max$. & Fail & $x$ \\
\hline & \multicolumn{3}{|c|}{$\begin{array}{r}\text { Lateral friction utilization, at high speed, (HFU) } \\
\text { Axle group }\end{array}$} & $\begin{array}{l}23.3 \% \\
4: 7\end{array}$ & $80 \%$ & $\max$ & Pass & $\checkmark$ \\
\hline$f$ & \multicolumn{3}{|c|}{ Yaw damping ratio, (YDR), (NRC) } & 0.1325 & 0.15 & $\min$. & Fail & $x$ \\
\hline
\end{tabular}

\subsection{Discussion of the results}

Referring to table 1., the results obtained based on both RTAC and NRC methods are to be discussed from the following view points:

\section{a. Rollover stability}

Rollover stability is considered as the most important performance measure in evaluating the dynamic performance of the heavy vehicles, so it is examined from different points of view as follows:

Static rollover threshold: The static rollover threshold, which is predicted from both static roll model and yaw/roll model ( 0.46 and 0.522 respectively), indicates that, the vehicle has a good level of rollover stability, the threshold limit is $(0.4$,minimum).

Dynamic rollover stability: Which is expressed in terms of load transfer ratio and rearward amplification ratio. The results obtained from RTAC method $(0.333$ and 1.26 respectively) ensure that the vehicle has a good rollover stability, where the threshold limits are (0.6 and 2.2, maximum).

\section{b. Handling characteristics}

As discussed before, handling characteristics is a good measure of both the controllability and stability of the vehicle. NRC three point handling curve inclicates a good yaw stability and controllability of the case studied, and this may be referred to the increased number of semitrailer rear axles. 


\section{c. Offtracking performance}

Offtracking performance is a measure showing the ability of the combination to track different curvatures with different speeds. The calculations of offtracking obtained from RTAC method give good results.

\section{d. Friction demand properties}

The friction demand measure describes the tire friction levels measured at the drive axle of the tractor during low and high-speed maneuvers. The results obtained based on RTAC method show that low level of the friction demand, which gives impression of low possibility of jackknifing occurrence. This may be attributed to the higher load at the tractor drive axles.

\section{e. Lateral friction utilization}

Characterize the level of lateral friction utility at an axle group of the combination axles. The results obtained based on RTAC method show increased lateral friction utility at the tractor front axle at low speed maneuvers $(87 \%)$, where the threshold limit is $(80 \%)$, which may be an indicator to the loss of the steering control, moreover the side skidding of the tires gives excessive tire wear.

\section{f. Yaw damping ratio coefficient}

The yaw damping measure describes how rapidly the lateral acceleration oscillations of the rearmost trailer of an articulated vehicle diminish. It is a new measure developed by NRC. The calculation of yaw damping ratio based on NRC method $(0.1325)$ shows low level of the damping ratio results in prolonged swaying, where the threshold limit is $(0.15$, minimum).

\section{Final evaluation:}

For the case studied, it is found that, the combination has a good dynamic rollover stability, yaw stability, controllability and friction demand, while it has undesirable lateral friction utilization and yaw damping ratio, which indicates tendency for uncontrollable behavior of the combination may occur. It should be noted that, it is reported for this combination that there is an extra tire wear, which explains that the tires work near the adhesion limit leading to a tire side skid. Also prolonged swaying of the semitrailer increases this side skidding, which results in more tires failure.

\section{CONCLUSIONS}

1. A systematic method based on computer simulation has been highlighted and applied on an actual case study.

2. This method can be used in the national scale to evaluate the controllability and stability limits for heavy articulated vehicles.

3. For the case study considered the combination has passed all tests except lateral friction utilization (LFU) and yaw damping ratio (YDR), where the simulation results give a value of $87 \%$ for LFU, while the maximum limit is $80 \%$, and a value of 0.132 for YDR, while it should be grater than 0.15 . These results may explain the complaint of the excessive tire wear of the considered combination. More investigation is needed to compensate for these unsatisfactory responses. 


\section{REFERENCES}

[1] Ervin, R. D. and Guy, Y. "The Influence of Weights and Dimensions on the Stability Control of Heavy Trucks in Canada- Part 1", Technical Report, Vol. 1, Vehicle Weights and Dimensions Study, RTAC, July 1986.

[2] EL-Gindy, M. "An Overview of Performance Measures for Heavy Commercial Vehicles in North America", Center for Surface Transportation Technology, National Research Council of Canada, 1995.

[3] EL-Gindy, M. and Preston Thomas, J. "Static Rollover Threshold of Heavy Trucks", Ground Transportation Technology Program, National Research Council Canada, 1992.

[4] Wong, J. Y. and EL-Gindy, M. "Computer Simulation of Heavy Vehicle Dynamic Behavior, User's Guide to the UMTRI Models", Technical Report 3, Vehicle Weights and Dimensions Study, RTAC, July 1985.

[5] Lin, R. C., Cebon, D., and Cole, D. J. "Validation of an Articulated Vehicle Yaw/Roll Model", University of Cambridge, CUED/C-MECH/TR53, Sept. 1993.

[6] "International Component Book", PDB-70000NB, April, 1992 Edition, Part of CT-400.

[7] El-Gindy, M. and Woodrooffe, J. H. F. "Influences of Tractor Wheel base, Tandem Axle Spread and Fifth-wheel Offset on Commercial Vehicle Dynamics", Technical Report No. TR-VDL-003, Vehicle Dynamic Laboratory, National Research Council of Canada, Ottawa, 1991.

[8] Winkler, C. B. "The Measurement of Inertial Properties and Suspension Parameters of Heavy Highway Vehicles", Paper SAE 730182 presented at SAE International Automotive Engineering Congress, Detroit, January 1973.

[9] Fancher, P. S., Ervin, R. D., Winkler, C. B., and MacAdann, C. C. "Measurement and Representation of the Mechanical Properties of Truck Leaf Springs", Highway Safety Research Institute, SAE Paper No.800905, 1980.

[10] Winkler, C. B., Karamihas, S. M., and Board, S. E. "Roll Stability Performance of Heavy Vehicle Suspensions", University of Michigan Transportation Research Institute, SAE Paper No. 922426, March 1992.

[11] Pedro, Y. "Measurement of Radial Truck Tire Dry Cornering Characteristics", The Goodyear tire corporation, SAE Paper No.912677. 1991. 
ArRENUIX (A) LIST OF THE CASE STUDY INPUT DATA

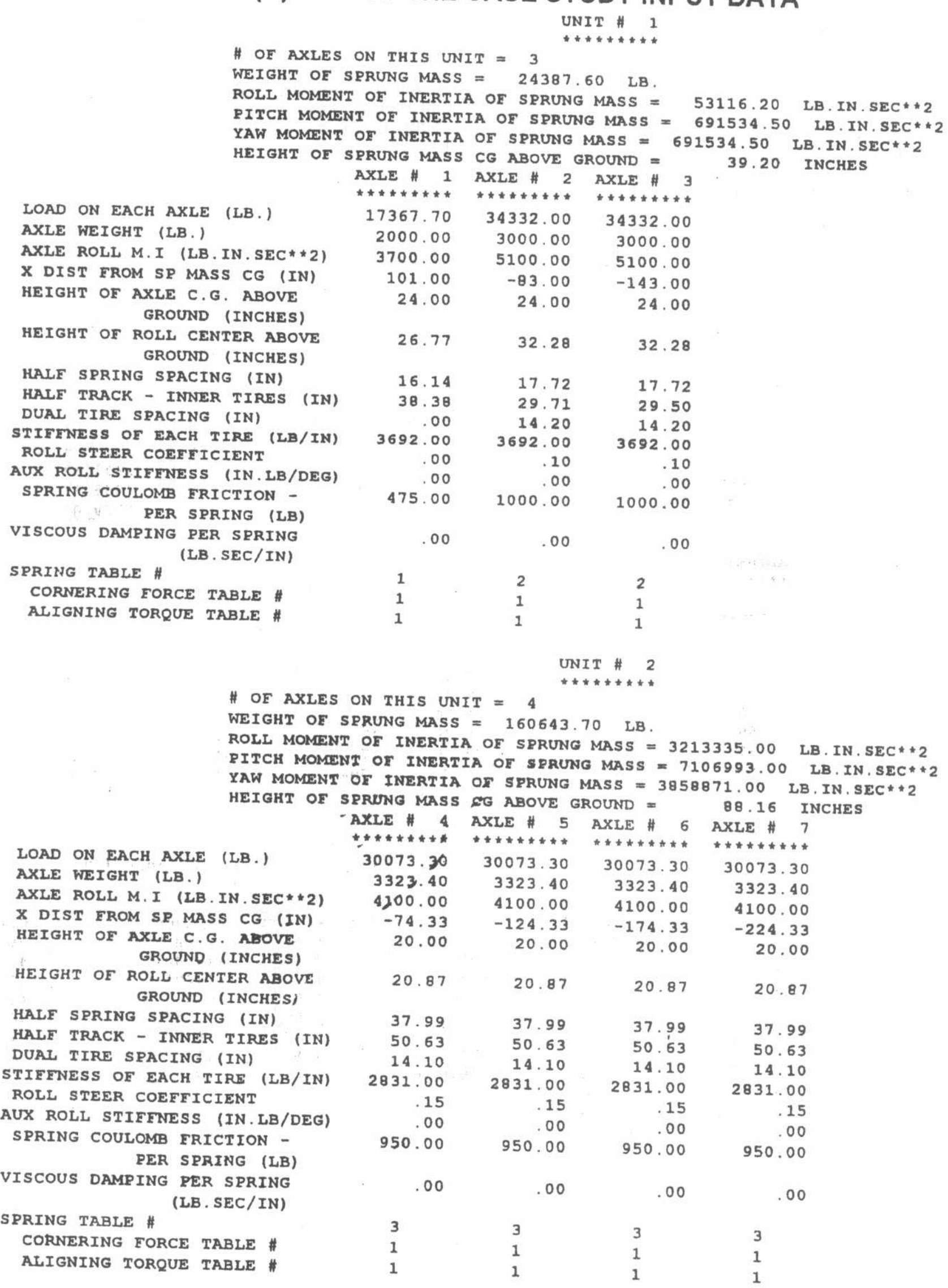


GROSS VEHICLE WEIGHT FORWARD VELOCITY

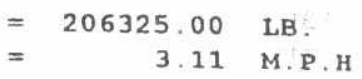

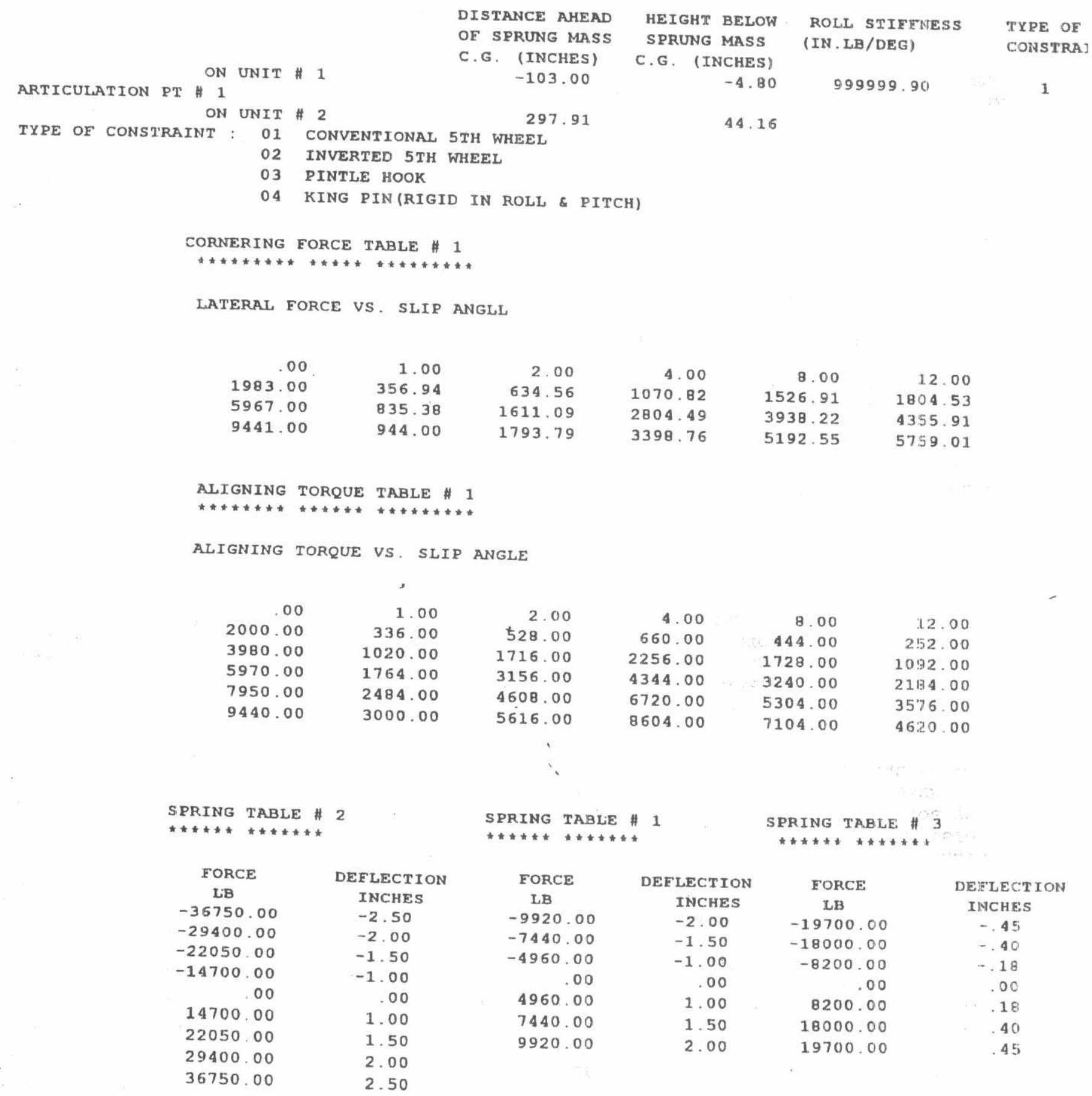




\section{Appendix (B) Conversion Factors}

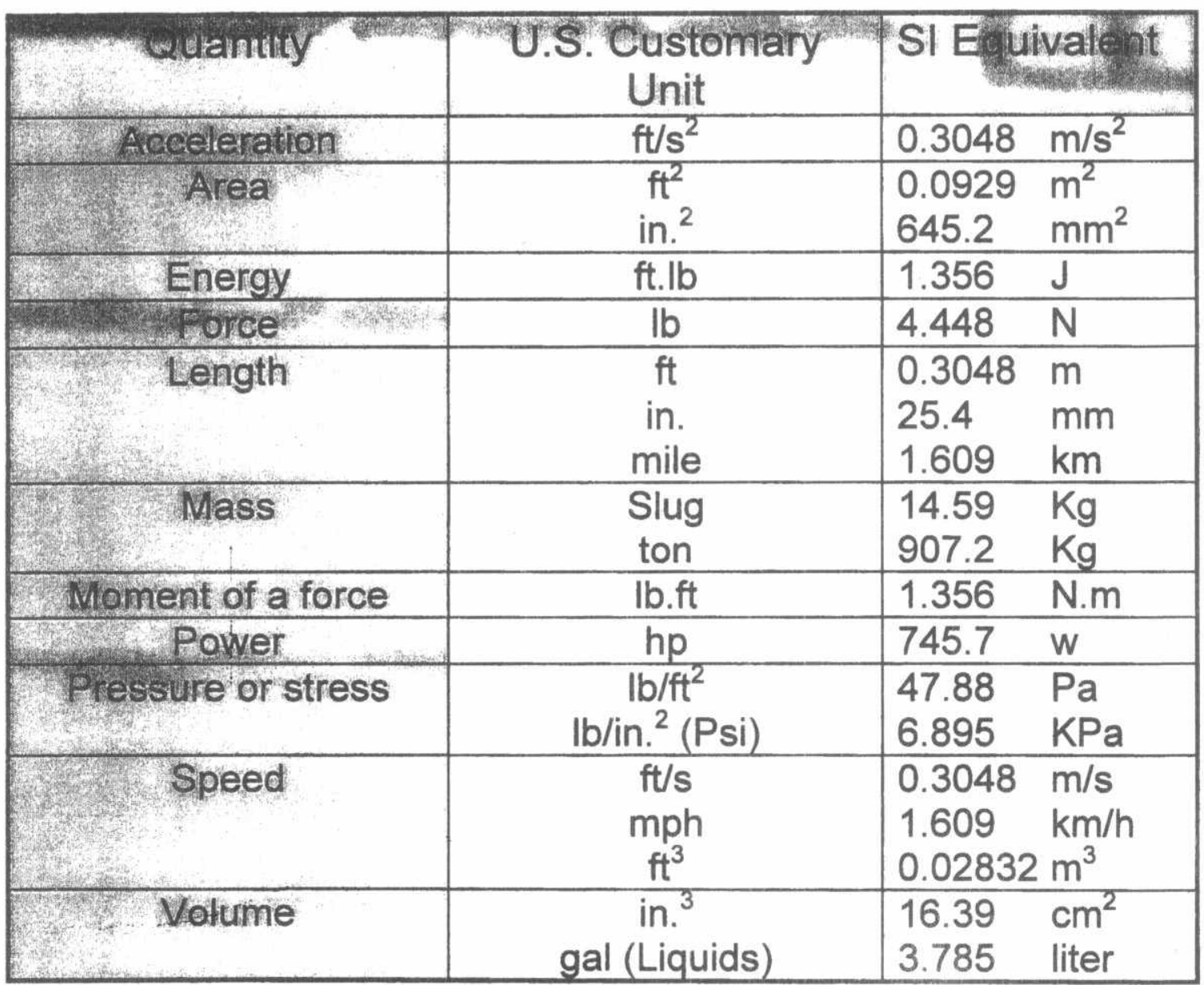

